\title{
ASSOCIATION OF LONG-TERM DIETARY FAT INTAKE, \\ EXERCISE, AND WEIGHT WITH LATER COGNITIVE FUNCTION IN THE FINNISH DIABETES PREVENTION STUDY
}

\section{Lehtisalo, J.}

2016-02

Lehtisalo , J , Lindstrom , J , Ngandu , T , Kivipelto , M , Ahtiluoto , S , llanne-Parikka , P , Keinanen-Kiukaanniemi , S , Eriksson , J G , Uusitupa , M , Tuomilehto , J , Luchsinger , J \& Finnish Diabet Prevention Study DP 2016 , ' ASSOCIATION OF LONG-TERM DIETARY FAT INTAKE, EXERCISE, AND WEIGHT WITH LATER COGNITIVE FUNCTION IN THE FINNISH DIABETES PREVENTION STUDY ' , Journal of nutrition, health \& aging , vol. 20 , no. 2 , pp. 146-154 . https://doi.org/10.1007/s12603-015-0565-1

http://hdl.handle.net/10138/224001

https://doi.org/10.1007/s12603-015-0565-1

publishedVersion

Downloaded from Helda, University of Helsinki institutional repository.

This is an electronic reprint of the original article.

This reprint may differ from the original in pagination and typographic detail.

Please cite the original version. 


\title{
ASSOCIATION OF LONG-TERM DIETARY FAT INTAKE, EXERCISE, AND WEIGHT WITH LATER COGNITIVE FUNCTION IN THE FINNISH DIABETES PREVENTION STUDY
}

\author{
J. LEHTISALO ${ }^{1,2}$, J. LINDSTRÖM ${ }^{1}$, T. NGANDU ${ }^{1}$, M. KIVIPELTO ${ }^{1,3,4}$, S . AHTILUOTO ${ }^{1,5}$, \\ P. ILANNE-PARIKKA ${ }^{6,7}$, S. KEINÄNEN-KIUKAANNIEMI ${ }^{8,9}$, J.G. ERIKSSON ${ }^{1,10,11,12}$, M. UUSITUPA ${ }^{13,14}$, \\ J. TUOMILEHTO ${ }^{15,16,17}$, J. LUCHSINGER ${ }^{18}$ FOR THE FINNISH DIABETES PREVENTION STUDY (DPS)

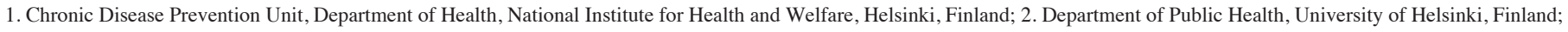 \\ 3. Aging Research Center, Karolinska Institutet, Stockholm, Sweden; 4. Department of Neurology, Institute of Clinical Medicine, University of Eastern Finland, Kuopio, Finland; \\ 5. Espoo City Hospital, Espoo, Finland; 6. Science Center, Tampere University Hospital, Tampere, Finland; 7. The Diabetes Center, Finnish Diabetes Association, Tampere, Finland; \\ 8. Institute of Health Sciences (General Practice), University of Oulu, Oulu, Finland; 9. Unit of General Practice, Oulu University Hospital and Health Centre of Oulu, Oulu, Finland;

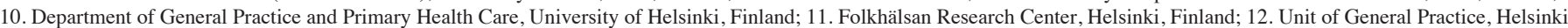 \\ University Central Hospital, Helsinki, Finland; 13. Institute of Public Health and Clinical Nutrition, Clinical Nutrition, University of Eastern Finland, Kuopio, Finland; 14. Research

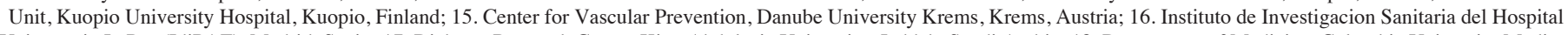

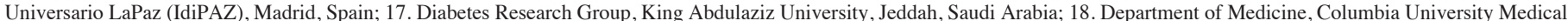

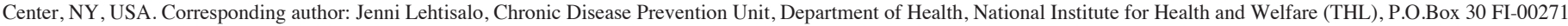 \\ Helsinki, Finland, Phone: +358 29524 8573, email: jenni.lehtisalo@thl.fi
}

\begin{abstract}
Objectives: To investigate associations of long-term nutrient intake, physical activity and obesity with later cognitive function among the participants in the Finnish Diabetes Prevention Study, in which a lifestyle intervention was successful in diabetes prevention. Design: An active lifestyle intervention phase during middle age (mean duration 4 years) and extended follow-up (additional 9 years) with annual lifestyle measurements, followed by an ancillary cognition assessment. Setting: 5 research centers in Finland. Participants: Of the 522 middle-aged, overweight participants with impaired glucose tolerance recruited to the study, $364(70 \%)$ participated in the cognition assessment (mean age 68 years). Measurements: A cognitive assessment was executed with the CERAD test battery and the Trail Making Test A on average 13 years after baseline. Lifestyle measurements included annual clinical measurements, food records, and exercise questionnaires during both the intervention and follow-up phase. Results: Lower intake of total fat $(\mathrm{p}=0.021)$ and saturated fatty acids $(\mathrm{p}=0.010)$, and frequent physical activity $(\mathrm{p}=0.040)$ during the whole study period were associated with better cognitive performance. Higher BMI $(\mathrm{p}=0.012)$ and waist circumference $(\mathrm{p}=0.012)$ were also associated with worse performance, but weight reduction prior to the cognition assessment predicted worse performance as well (decrease vs. increase, $\mathrm{p}=0.008$ for BMI and $\mathrm{p}=0.002$ for waist). Conclusions: Long-term dietary fat intake, BMI, and waist circumference have an inverse association with cognitive function in later life among people with IGT. However, decreases in BMI and waist prior to cognitive assessment are associated with worse cognitive performance, which could be explained by reverse causality.
\end{abstract}

Key words: Cognition, diet, weight, prevention

\section{Introduction}

Type 2 diabetes (T2D) is associated with cognitive decline and an increased risk for dementia in many studies (1), and cognitive decline and diabetes share several risk and protective factors. Recent meta-analyses show that adherence to the Mediterranean Diet (2) and physical activity (3) are associated with lower risk, and midlife obesity with an increased risk of dementia and cognitive decline (4). So far the evidence of the importance of lifestyles in cognitive decline comes mainly from observational studies. One lifestyle trial with cognition as a secondary outcome suggests better cognitive functions with the Mediterranean diet (5), but there are very few studies investigating long-term lifestyle changes and cognitive function in a controlled study design.

The Finnish Diabetes Prevention Study (DPS) showed that $\mathrm{T} 2 \mathrm{D}$ risk can be decreased by $58 \%$ with a lifestyle intervention (6). Better results were achieved with increasing number of lifestyle goals achieved. Due to shared risk factors we hypothesized that these lifestyle changes could be protective against cognitive decline, and completed ancillary cognitive assessment for the DPS participants on average 13 years after the study baseline. Intention to treat analyses showed no difference between the lifestyle intervention group and the control group in cognitive performance (7). However, the association between particular lifestyles and cognitive performance were not examined. The aim of this secondary analysis is to investigate how lifestyle factors and changes in them from midlife to older age are associated with later cognitive performance. Specifically, we studied cognitive function in relation with dietary fat and fiber intake, weight, waist circumference and physical activity, the original targets of DPS lifestyle intervention, measured over a 13-year period. 


\section{JNHA: CLINICAL NEUROSCIENCES}

\section{Methods}

\section{Subjects and setting}

This study was a sub-study to the DPS which has been described in detail previously (8). In brief, the DPS was a randomized, controlled, multi-center lifestyle intervention study aiming at type 2 diabetes prevention in a high-risk population (ClinicalsTrials.govNCT00518167). Participants were middle-aged (mean 55 years at randomization, range 40 to 65 years), overweight or obese (BMI > $25 \mathrm{~kg} / \mathrm{m} 2$ ), and had impaired glucose tolerance (IGT) at baseline. The intervention group $(n=265)$ received frequent individualized dietary, physical activity, and weight reduction counseling by the study nutritionist at 7 face-to-face counselling sessions during the first intervention year and every 3 months thereafter until the end of the intervention phase or diagnosis of diabetes. Voluntary free-of-charge supervised exercise sessions at the gym were also offered to the intervention group participants. The control group $(n=257)$ received only general health advice at baseline. The intervention phase was originally planned to continue for 6 years for each participant, but was prematurely discontinued based on the interim analyses showing a strong benefit in the lifestyle intervention group. Consequently, the average duration of the intervention phase was 4 years (range 1-6 years). The active intervention was followed by post-intervention follow-up phase with annual examinations. Cognition sub-study was initiated in 2009 , on average 9 years after the end of the intervention phase (13 year after the randomization). The DPS study protocol was originally approved by the ethics committee of the National Public Health Institute in Helsinki, and the North Ostrobothnia Hospital District approved the follow-up study and the cognition study. All participants gave written informed consent at baseline, at the beginning of the follow-up, and prior to the cognitive assessments.

\section{Clinical Measurements}

Baseline and annual examinations comprised 2-hour oral glucose tolerance test (OGTT), a medical history, and a physical examination with measurements of height (without shoes), weight (in light indoor clothes), waist circumference (midway between the lowest rib and iliac crest to the nearest $1 \mathrm{~mm}$ ) and systolic and diastolic blood pressure (two measurements with a standard sphygmomanometer in sitting position, using the right arm, after 10 minutes of rest). BMI was calculated dividing body weight $(\mathrm{kg})$ with the squared height (m2); for each person, the height measured at baseline was used for all time points. Average BMI $\left(\mathrm{kg} / \mathrm{m}^{2}\right)$ and waist circumference $(\mathrm{cm})$ based on all available measurements during the study period were calculated. The Apolipoprotein E (APOE) genotypes were analysed using the polymerase chain reaction (PCR) with slight modifications, as described elsewhere (9).

\section{Lifestyle assessment}

A 3-day food record was completed and analysed at baseline, three times during the active intervention phase (years 1,2 and 3 ), and twice during the follow-up. Recording was facilitated with a picture booklet, and completed records were checked by the study nutritionist. Nutrient intakes were calculated using a dietary analysis program and database developed in the Finnish National Public Health Institute (10). Average daily intakes of energy from total fat $(\mathrm{E} \%)$, energy from saturated fat (SFA; E\%) and dietary fiber (g) were calculated at baseline (intakes representing the time before the DPS) and averaged over the combined intervention and follow-up phase (intakes representing the time during the DPS). Changes in nutrient intakes were calculated by subtracting the baseline value from the averaged value.

Physical activity was self-reported. Participants reported their usual weekly frequency of physical activity with a fourcategory question, which was used to determine achievement of the exercise goal. They additionally filled in the validated Kuopio Ischemic Heart Disease (KIHD) risk factor study questionnaire (11) to assess annual leisure-time physical activity (LTPA) in more detail. Mean weekly amount of moderate-to-vigorous LTPA (hours) was calculated annually and averaged over the whole study period.

\section{Lifestyle goals}

The five main goals of the DPS lifestyle intervention were weight reduction of $5 \%$ or more; less than $30 \%$ of the energy from fat; less than $10 \%$ of the energy from SFA; fiber intake of $15 \mathrm{~g} / 1000 \mathrm{kcal}(3.6 \mathrm{MJ})$ or more; and moderate intensity physical activity $30 \mathrm{~min} /$ day or more in average. Achievement of the dietary goals was determined based on mean intake during the intervention phase. Percentual weight change from baseline was defined at year 3 , as well as physical activity response, using the last observation carried forward to replace missing values.

\section{Cognitive assessment}

The cognitive assessment was conducted twice: in 2009, on average 13 years after the DPS baseline, and again in 2011. All eligible participants in both former intervention and control groups (excluding those who had withdrawn from the study or died) were mailed an invitation letter to participate. Cognitive function was assessed by trained study nurses using the Consortium to Establish a Registry for Alzheimer's Disease (CERAD) (12) neuropsychological test battery (standardized Finnish translation) which is a sensitive measure for cognitive changes observed in Alzheimer's disease, and Trail Making Test A (TMT) (letters) that measures visuomotor speed/ executive function (13). All participants with at least one cognitive assessment ( $n=364$ for CERAD, $n=362$ for TMT) were included using the first available observation for each.

The Finnish CERAD Battery is composed of 1) Verbal fluency (animals) 2) Modified Boston Naming test (15 


\section{ASSOCIATION OF LONG-TERM DIETARY FAT INTAKE, EXERCISE, AND WEIGHT WITH LATER COGNITIVE FUNCTION}

words) 3) Mini-Mental State Exam 4) Word List Memory (ten words, three trials) 5) Constructional praxis 6) Word List Recall (delayed recall of the ten words) 7) Word List Recognition (recognition of the ten words out of 20 words) 8) Constructional praxis recall 9) Clock drawing. We calculated the CERAD total score (CERAD-TS) to measure overall cognitive performance according to Chandler et al (14). The TMT was calculated as time in seconds without upper limit (longer time indicating worse performance).

\section{Weight and waist change profiles}

For BMI and waist circumference, separate mean values were calculated for the active intervention phase and for the follow-up phase. Weight change categories were determined first as weight loss vs. weight gain during the intervention phase; then as loss vs. gain from intervention to followup phase. Similar categorization was applied for waist circumference. Finally, change profiles for BMI and waist were defined as follows: 1) decrease (during intervention) + decrease (during follow-up); 2) decrease + increase; 3 ) increase + decrease; 4) increase + increase, respectively.

\section{Statistical Methods}

Baseline characteristics were compared using t-test or $\mathrm{chi}^{2}{ }_{-}$ test as applicable. Linear regression modeling was applied in all cognition analyses. We first adjusted for age and education (Model A), with education being both a surrogate for socioeconomic status and for cognitive reserve. In the second model (Model B) additional adjustments were made for sex, APOE E4 carrier status, baseline smoking, baseline systolic blood pressure, and intervention allocation. Missing baseline systolic blood pressure values $(n=2)$, education $(n=1)$ and smoking $(n=1)$ were replaced with values measured at year 1. APOE $\varepsilon 4$ carrier status was coded as 1 for any APOE $\varepsilon 4$ and 0 for none. For missing APOE information $(n=10)$ replacement with value 0.5 was applied and variable was entered as continuous.

Cognitive scores were skewed to the right, and box-cox transformation (15) improved normality. Hence all regression analyses were conducted with transformed cognition scores. For the amount of physical activity, distribution was skewed to the left and square-root transformation was applied. The transformations did not change results markedly, and we present the regression estimates using non-transformed models to facilitate interpretation. All p-values presented are based on models using box-cox transformation (and square-roottransformation, where applicable). One influential outlier in the CERAD-TS, scoring 38 points, was removed from the final analysis, although keeping the outlier in the model would not have changed the presented results.

First, the compliance to the original DPS lifestyle intervention goals was analysed for the intervention phase and a success score indicating the total amount of goals was calculated. Second, linear models were run to investigate the linear association between cognitive performance and general level of the same lifestyle factors and changes in them, using data from all available years. Furthermore, weight change profiles were analysed as factor variables.

We have previously reported that there were no differences in cognition between the former intervention and control groups in cognitive performance (7), and therefore all analyses in this paper were performed for the whole group combined, adjusting for the intervention allocation.

Analyses were conducted with STATA for Windows, release 11.2 (StataCorp LP, TX). p-value $<0.05$ was considered statistically significant.

\section{Results}

\section{Characteristics}

The cognition study included 364 participants (70\% of the original DPS cohort). The participants had lower systolic blood pressure at baseline and during the study period, but there were no other differences compared with the non-participants (Table 1). The mean age was $55.1 \pm 6.8$ years at baseline and $68.3 \pm 6.8$ years at cognition assessment. The cognition was assessed on average 13 years after the baseline visit (range 11 to 18 years, due to lengthy recruitment period) and the average time between the last lifestyle measurement and the cognition assessment was 4 years for dietary variables and 2 years for weight and physical activity variables. The median number of measurements was for dietary intake 5 (range 1 to 5 ); for physical activity 9 (range 1 to 12); and for BMI and waist circumference 10 (range 2 to 12). Lifestyle factors at baseline or during the study did not differ between participants and nonparticipants of the cognition study (results not shown).

Figure 1

CERAD-TS according to the direction of weight change in different study phases (weight change profile)

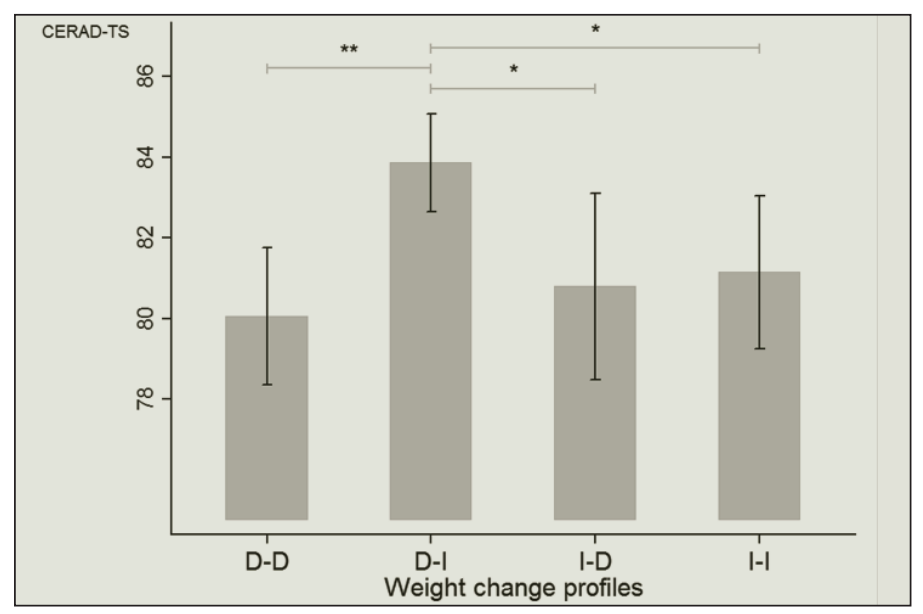

Groups are D-D) decrease (at intervention) + decrease (at follow-up) D-I) decrease + increase; I-D) increase + decrease; I-I) increase + increase. Data are presented as adjusted mean with error bars indicating 95\% CI. Group 2 as a reference group; model adjusted for age, education, sex, APOE $\varepsilon 4$ carrier status and smoking status, systolic blood pressure, and BMI at baseline. $* \mathrm{p}<0.05 * * \mathrm{p}<0.01$. 


\section{Achievement of lifestyle goals}

After three years of the intervention, $86 \%$ of the cognition study participants achieved at least one lifestyle goal, but only $3 \%$ achieved all five goals $(n=9)$. Achievement of each of the goals was more common among the intervention group ( $\mathrm{Chi}^{2}$ test, $\mathrm{p}<0.05$ for all). Achievement of the fat goal during the intervention phase was associated with better performance in the CERAD-TS, but other goals showed non-significant associations (Table 2). Higher number of goals achieved i.e. the high success score predicted better CERAD-TS ( $\mathrm{p}$ for trend 0.012). No association with the TMT was detected.

Table 1

Characteristics of the DPS cohort

\begin{tabular}{|c|c|c|c|}
\hline & $\begin{array}{c}\text { Cognition } \\
\text { study } \\
\text { participants } \\
(n=364)\end{array}$ & $\begin{array}{c}\text { Non- } \\
\text { participants } \\
(\mathrm{n}=158)\end{array}$ & p -value \\
\hline \multicolumn{4}{|l|}{ Age, years } \\
\hline At baseline & $55.1 \pm 6.8$ & $55.3 \pm 7.8$ & 0.793 \\
\hline Mean age during the study & $61.1 \pm 6.7$ & $60.2 \pm 7.9$ & 0.188 \\
\hline At the cognition study & $68.3 \pm 6.7$ & & \\
\hline High education, $\mathrm{n}(\%)^{\mathrm{a}}$ & $122(34 \%)$ & $50(32 \%)$ & 0.686 \\
\hline Women, n (\%) & $250(69 \%)$ & $100(63 \%)$ & 0.265 \\
\hline Intervention group, $\mathrm{n}(\%)$ & $184(51 \%)$ & $81(51 \%)$ & 0.924 \\
\hline APOE $\varepsilon 4$ carriers, $\mathrm{n}(\%)$ & $118(33 \%)$ & $46(34 \%)$ & 0.915 \\
\hline \multicolumn{4}{|l|}{ Diagnosed with diabetes, n (\%) } \\
\hline At baseline & 0 & 0 & \\
\hline After the intervention phase & $70(19 \%)$ & $46(29 \%)$ & 0.016 \\
\hline At the cognition study & $168(46 \%)$ & $68(43 \%)$ & 0.566 \\
\hline \multicolumn{4}{|l|}{ Fasting glucose, $\mathrm{mmol} / \mathrm{l}$} \\
\hline At baseline & $6.1 \pm 0.7$ & $6.2 \pm 0.8$ & 0.080 \\
\hline Mean during the study & $6.4 \pm 0.9$ & $6.5 \pm 0.9$ & 0.140 \\
\hline \multicolumn{4}{|l|}{ Systolic BP, mmHg } \\
\hline At baseline & $136.8 \pm 17.2$ & $140.9 \pm 18.4$ & 0.017 \\
\hline Mean during the study & $136.1 \pm 14.0$ & $139.6 \pm 14.8$ & 0.011 \\
\hline \multicolumn{4}{|l|}{ Cognition scores } \\
\hline CERAD Total Score & $82.0 \pm 9.3$ & & \\
\hline TMT-A & $48.6 \pm 19.6$ & & \\
\hline
\end{tabular}

Data are mean $\pm \mathrm{SD}$ if not specified otherwise. a. At baseline

\section{Lifestyle factors at baseline and lifestyle change during the study}

Neither diet nor physical activity at baseline was related to the cognitive performance (Table 3 ).

Lower intake of total fat and SFA during the whole study period, as well as greater reduction in either one predicted better performance in CERAD-TS. Lower BMI or waist circumference at baseline and during the study was associated with better CERAD-TS. In addition, greater amount of moderate-to-vigorous physical activity during the study was associated with better CERAD-TS. These results remained virtually unchanged when excluding those with less than 3 lifestyle measurements $(n=2-37$ depending on the variable), or those with no data from the follow-up phase $(n=7-77)$. However, the association between physical activity and CERAD-TS became non-significant by both exclusions (results not shown).

\section{Weight change profiles}

We found no differences in cognition between participants with weight loss vs. those with weight gain during the intervention phase, whereas weight loss between the intervention and follow-up phases predicted poorer performance in CERAD-TS ( $\mathrm{p}=0.008$ with full adjustment). Weight loss during the intervention followed by weight gain thereafter (profile "D-I") predicted significantly better CERAD-TS compared with any other weight profile (Figure 1). Other groups did not differ from each other. The group with decreased waist circumference from baseline to the intervention phase had better performance in CERAD-TS than those with increased waistline ( $\mathrm{p}=0.007$, fully adjusted model), whereas those with decrease from the intervention to the follow-up phase performed worse $(\mathrm{p}=0.004)$. The waist change profile with decrease during the intervention and increase thereafter (profile "D-I") was significantly advantageous in CERAD-TS (Figure 2). The TMT results were non-associated with weight or waist changes (data not shown).

\section{Figure 2}

CERAD-TS (adjusted mean and 95\% CI) according to the direction of change in waist circumference in different study phases (waist change profile)

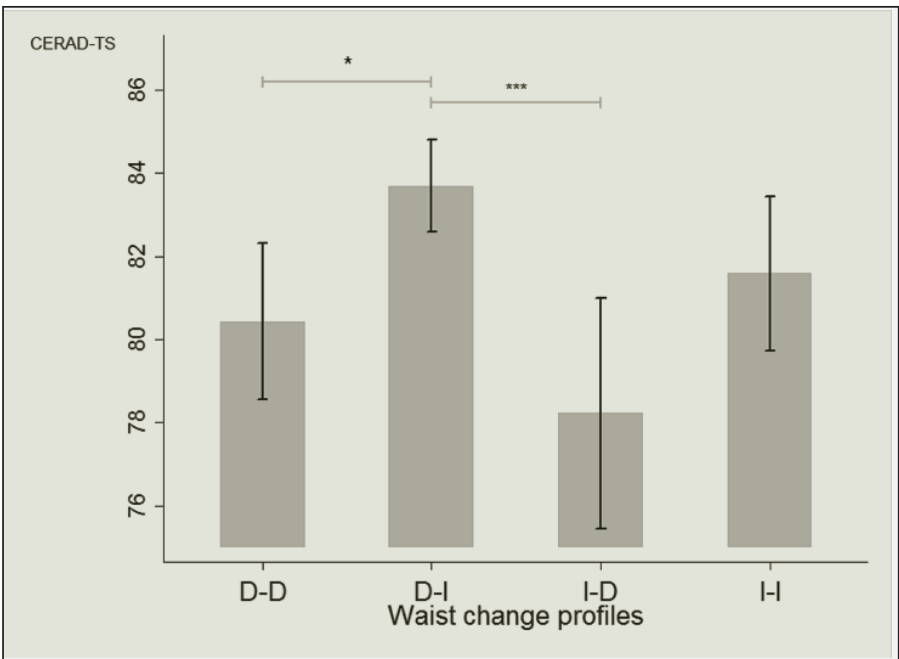

Groups are D-D) decrease (at intervention) + decrease (at follow-up) D-I) decrease + increase; I-D) increase + decrease; I-I) increase + increase. Data are presented as adjusted mean with error bars indicating 95\% CI. Group 2 as a reference group; model adjusted for age, education, sex, APOE $\varepsilon 4$ carrier status and smoking status, systolic blood pressure, and BMI at baseline. $* \mathrm{p}<0.05$ 
Table 2

Achievement of the DPS goals at year 3 and later cognition scores

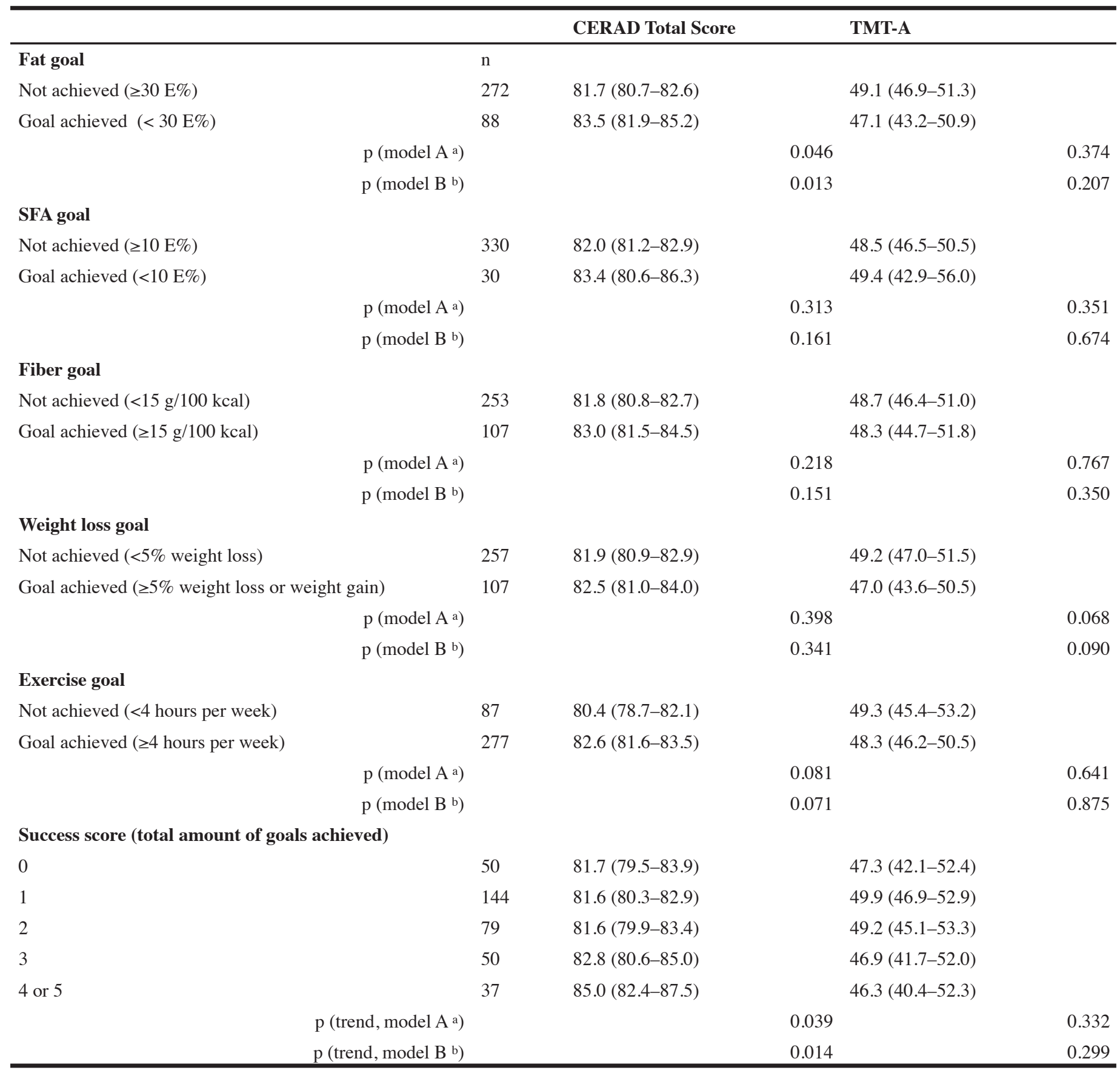

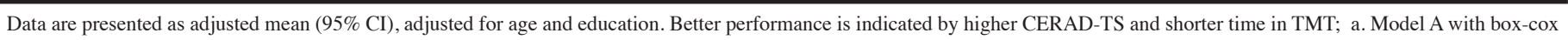

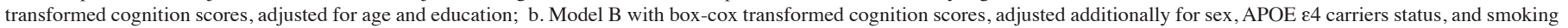
status, systolic blood pressure, and intervention allocation.

\section{Discussion}

Our results show that a long-term healthier lifestyle and positive lifestyle changes are associated with better cognition later in life among a population with IGT at baseline. Obesity measures appeared to have a two-sided relationship as lower BMI and waist circumference at baseline and during the intervention phase were associated with better cognitive function, whereas declining weight prior to cognitive assessment predicted poorer cognition, possibly due to reverse causality.

Dietary intervention studies focusing on cognitive 
Table 3

Mean level of the lifestyle factors during the study and their mean change in association with later cognitive performance

Lifestyle factors and their mean levels during the study
Linear associations with the cognition

CERAD TOTAL SCORE

mean \pm SD

b

TMT-A

\begin{tabular}{|c|c|c|c|c|c|c|c|}
\hline & mean \pm SD & $\mathbf{b}$ & $(95 \% \mathrm{CI})$ & p-value & $\mathbf{b}$ & $(95 \% \mathrm{CI})$ & p-value \\
\hline \multicolumn{8}{|l|}{ FAT INTAKE (E\%) } \\
\hline At baseline & $36.6 \pm 6.6$ & 0.00 & $(-0.13-0.13)$ & 0.931 & -0.04 & $(-0.34-0.25)$ & 0.385 \\
\hline Mean level during the study & $33.1 \pm 4.7$ & -0.24 & $(-0.43--0.04)$ & 0.021 & 0.31 & $(-0.14-0.75)$ & 0.228 \\
\hline Mean change & $-3.5 \pm 6.7$ & -0.27 & $(-0.47--0.06)$ & 0.013 & 0.37 & $(-0.10-0.85)$ & 0.106 \\
\hline \multicolumn{8}{|l|}{ SFA INTAKE (E\%) } \\
\hline At baseline & $16.6 \pm 4.2$ & -0.09 & $(-0.30-0.12)$ & 0.472 & 0.10 & $(-0.37-0.57)$ & 0.836 \\
\hline Mean level during the study & $13.5 \pm 2.9$ & -0.41 & $(-0.73--0.09)$ & 0.010 & 0.65 & $(-0.08-1.38)$ & 0.061 \\
\hline Mean change & $-3.1 \pm 4.1$ & -0.41 & $(-0.75--0.07)$ & 0.014 & 0.67 & $(-0.11-1.45)$ & 0.039 \\
\hline \multicolumn{8}{|l|}{ FIBER INTAKE (g/1000 kcal) } \\
\hline At baseline & $11.7 \pm 4.0$ & 0.00 & $(-0.22-0.22)$ & 0.780 & 0.35 & $(-0.15-0.84)$ & 0.032 \\
\hline Mean level during the study & $13.3 \pm 3.5$ & 0.10 & $(-0.16-0.36)$ & 0.457 & 0.11 & $(-0.49-0.71)$ & 0.627 \\
\hline Mean change & $1.6 \pm 3.7$ & 0.13 & $(-0.17-0.43)$ & 0.313 & -0.13 & $(-0.82-0.56)$ & 0.519 \\
\hline \multicolumn{8}{|c|}{ MODERATE-TO VIGOROUS-LTPA (h/week) } \\
\hline At baseline & $2.7 \pm 3.1$ & 0.11 & $(-0.18-0.39)$ & 0.127 & -0.20 & $(-0.85-0.45)$ & 0.186 \\
\hline Mean level during the study & $3.4 \pm 2.7$ & 0.26 & $(-0.05-0.57)$ & 0.040 & -0.19 & $(-0.91-0.52)$ & 0.538 \\
\hline Mean change & $0.7 \pm 2.4$ & 0.25 & $(-0.11-0.60)$ & 0.170 & -0.13 & $(-0.95-0.69)$ & 0.949 \\
\hline \multicolumn{8}{|l|}{$\mathrm{BMI}\left(\mathrm{kg} / \mathrm{m}^{2}\right)$} \\
\hline At baseline & $31.2 \pm 4.5$ & -0.20 & $(-0.39--0.01)$ & 0.041 & 0.02 & $(-0.41-0.45)$ & 0.744 \\
\hline Mean level during the study & $30.8 \pm 4.7$ & -0.23 & $(-0.41--0.04)$ & 0.011 & 0.11 & $(-0.31-0.53)$ & 0.308 \\
\hline Mean change & $-0.5 \pm 1.5$ & -0.32 & $(-0.81-0.18)$ & 0.090 & 0.70 & $(-0.44-1.84)$ & 0.050 \\
\hline \multicolumn{8}{|l|}{ WAIST (cm) } \\
\hline At baseline & $101.3 \pm 11.0$ & -0.10 & $(-0.17--0.02)$ & 0.022 & -0.01 & $(-0.19-0.17)$ & 0.860 \\
\hline Mean level during the study & $100.5 \pm 11.5$ & -0.09 & $(-0.16--0.02)$ & 0.012 & 0.04 & $(-0.13-0.21)$ & 0.389 \\
\hline Mean change & $-0.7 \pm 4.6$ & -0.08 & $(-0.25-0.09)$ & 0.191 & 0.25 & $(-0.14-0.64)$ & 0.085 \\
\hline
\end{tabular}

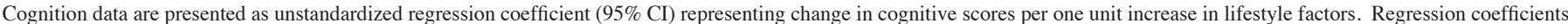

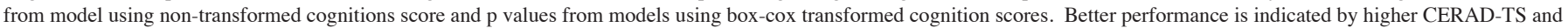
shorter time in TMT. Model adjusted for age, education, sex, APOE $\varepsilon 4$ carrier status and smoking status, systolic blood pressure, and BMI at baseline.

outcomes are scarce. The DASH-diet, originally developed to decrease hypertension, improved cognitive function (16) over 4 months, but so far no long-term dietary intervention studies investigating cognitive changes are available. One cardiovascular disease prevention trial suggested that Mediterranean diet was beneficial for cognition after 6 years of intervention (5), but unfortunately this study lacks the baseline cognition assessment as does our study. In the DPS, cognitive performance did not differ between the intervention and control groups despite the difference in diabetes incidence. Lifestyle changes reported in this paper may partially explain the lack of differences; both groups actually improved their lifestyle during the study, and this may have diluted the differences between the groups. The control group actually also received health advice and monitoring, although with less intensity than the intervention group.

Our results showing that both total fat and SFA are associated with worse cognitive function are in line with previous epidemiological studies concerning SFA (17-19), although not all studies confirm this association (20). Total fat intake has been associated with increased risk for AD (21, 22 ), and total fat intake from milk and spreads with poorer cognitive function (17). Other fatty acids such as higher intake of monounsaturated fatty acids (19) or lower ratio of polyunsaturated fatty acids to SFA (18) have also been associated with better cognitive function in these studies. To 
our knowledge, this is the first study linking reduction in total fat/SFA intake to better cognitive function. We only focused on fats that were emphasized in the original DPS intervention, which is one of the limitations in our study. Some studies also suggest a positive association between fiber intake and cognitive function $(23,24)$, although we found no evidence of such relationship. Fiber intake in Finland is relatively high, and was additionally emphasized in the lifestyle intervention, which may result in less variability between the participants.

Physical activity has been linked to less cognitive decline and lower risk of $\mathrm{AD}(25)$, and lower risk of mild cognitive impairment (26), but associations were weaker among diabetic participants (27). The association we found was relatively weak and diminished after excluding those with only few measurements. There are only few studies investigating changes in physical activity in relation to cognition or dementia. One study focusing on physical activity (28) and other on leisure and social activities (29) both showed that remaining active over long time or becoming active was linked to lower risk of dementia later on. Short-term clinical trials (6 months) have shown some benefits among those with mild cognitive impairment $(30,31)$ and also among participants with glucose intolerance (32).

Our findings about associations between higher BMI or waist circumference and worse cognitive performance are in agreement with previous prospective studies $(33,34)$, but findings regarding weight loss are more controversial. Stable weight has been suggested the most beneficial (35), and weight loss 5 years prior to the cognitive assessment has predicted poorer results (36), in accordance with our study. However, we also found decline in waistline to predict poorer cognition, whereas other studies found no evidence for a relationship between waist change and cognitive function $(35,36)$.

Interestingly, among our overweight participants, a combination of weight loss during the intervention phase but no weight loss thereafter appeared the most beneficial. Weight loss during the intervention was presumably intentional, whereas the weight change thereafter may be confounded by unintentional weight loss, which can be a sign of pre-clinical AD (37). A small pilot study indicated that intentional weight loss would be beneficial for cognitive function (38), but another trial aiming to weight loss among diabetes patients had no effect on cognition assessed cross-sectionally later in life (39). Weight loss close to cognitive assessment could be a marker, rather than a cause, of underlying cognitive or other health problems. Furthermore, our participants were older during the follow-up and the associations between traditional risk factors and cognitive functions may change with age due to reverse causality. Several studies have demonstrated a decline in weight, blood pressure or cholesterol prior to diagnosis of dementia (40), and for example presence of the metabolic syndrome has actually been linked to less cognitive decline in old age (41).

Among the strengths of our study are the repeated lifestyle measurements that were carried out frequently and using relatively precise methods such as food diaries and detailed KIHD questionnaire during a long period of time. We were also able to assess changes in lifestyle over a long time which is not usually possible. Most of the previous studies use only one single dietary assessment. Averaging several measurements gives a more reliable estimate for dietary intake over a long time. For obesity measures we had even more frequent time series and thus were able to see different patterns in weight changes.

There are also limitations that need to be addressed. Most importantly, the cognitive measurement was conducted only at the end of the study and no data on baseline cognition were collected. Therefore it is possible that those who achieved and maintained healthier lifestyle during the study may have had better cognition to start with. However, we had a relatively young group of participants, with a relatively high level of cognitive function even at the end of our follow-up study. Due to the long follow-up there were also drop-outs, and only $70 \%$ of the original cohort participated in the cognition study. Those with cognitive or other health problems may have been unable to participate, even though the baseline characteristics of the cognition cohort did not differ markedly from the entire cohort. Our analyses were focused on the lifestyles that were subject to the original intervention of the DPS, whereas other lifestyle factors could also have affected cognitive function along with the studied factors. Furthermore, we were not able to distinguish intentional and unintentional weight reduction, which, like said before, could have opposite effects on cognition. Lack of statistical power may also have an impact on the analyses between cognition and separate goals, as not so many participants achieved the lifestyle goals. Furthermore, all our participants had an increased risk of diabetes at baseline, and almost half of them developed diabetes during the study, and therefore the results of our study are best generalizable to persons with IGT.

Lifestyle interventions have become standard of care for persons with IGT, and our results highlight the potential importance of lifestyle factors in maintaining good cognitive functions in this population also in older age. Furthermore, the DPS intervention goals indicate the benefits with a multigoal-approach: cognitive performance improved with the total amount of goals achieved. Multidomain interventions have been suggested to be best intervention strategy also to support healthy aging (42). However, due the previously reported lack of difference between the intervention and control groups it remains unclear whether a lifestyle intervention in mid-life is efficient enough to alter cognitive functions later in life as it has been shown to do with prevention of diabetes (43). The effect of intentional and unintentional weight loss, and also the effect of changes in diet and exercise in different time points in life on cognition deserves more investigation in future studies. Lifestyle intervention trials with cognitive functions as primary outcomes, cognition biomarkers, and long follow- 


\section{JNHA: CLINICAL NEUROSCIENCES}

up are necessary to confirm the potential benefits of lifestyle interventions on cognition.

Funding: This work was financially supported by the American Diabetes Association (grant \#7-08-CR-41; PI J.A.L), Juho Vainio Foundation (JLe), and Yrjö Jahnsson Foundation (JLe). The DPS study has been supported by the Academy of Finland (128315, 129330), Ministry of Education, Novo Nordisk Foundation, Yrjö Jahnsson Foundation, Juho Vainio Foundation, Finnish Diabetes Research Foundation, Finnish Foundation for Cardiovascular Research, Unilever, and Competitive Research Funding from Tampere, Kuopio and Oulu University Hospitals.

Acknowledgements: The authors thank Tuomo Hänninen, Ph.D., and Teemu Paajanen, M.Psych., University of Eastern Finland, for their expertise and advice on neuropsychological issues, and Esko Levälahti, M.Sc., National Institute for Health and Welfare, for assistance and support in statistical analyses. The authors declare no conflicts of interest related to this manuscript.

Conflicts of interest: Dr. Luchsinger has been a consultant to Nutricia, Inc. in the role of nutrients in cognition. The other authors have nothing to disclose.

Ethical standards: This study has been performed according to the Declaration of Helsinki, and all participants have provided a written informed consent. The study design has been approved by the Ethics Committee of the National Public Health Institute of Finland.

\section{References}

1. McCrimmon RJ, Ryan CM, Frier BM. Diabetes and cognitive dysfunction. Lancet 2012;379:2291-2299. doi: 10.1016/S0140-6736(12)60360-2.

2. Singh B, Parsaik AK, Mielke MM, Erwin PJ, Knopman DS, Petersen RC, Roberts RO. Association of mediterranean diet with mild cognitive impairment and Alzheimer's disease: a systematic review and meta-analysis. J Alzheimers Dis 2014;39:271-282. doi: 10.3233/JAD-130830.

3. Sofi F, Valecchi D, Bacci D, Abbate R, Gensini GF, Casini A, Macchi C. Physical activity and risk of cognitive decline: a meta-analysis of prospective studies. J Intern Med 2011;269:107-117. doi: 10.1111/j.1365-2796.2010.02281.x.

4. Loef $M$ \& Walach H. Midlife obesity and dementia: meta-analysis and adjusted forecast of dementia prevalence in the United States and China. Obesity (Silver Spring) 2013;21:E51-55. doi: 10.1002/oby.20037.

5. Martinez-Lapiscina EH, Clavero P, Toledo E, Estruch R, Salas-Salvado J, San Julian B, Sanchez-Tainta A, Ros E, Valls-Pedret C, Martinez-Gonzalez MA. Mediterranean diet improves cognition: the PREDIMED-NAVARRA randomised trial. J Neurol Neurosurg Psychiatry 2013;84:1318-1325. doi: 10.1136/jnnp-2012-304792.

6. Tuomilehto J, Lindström J, Eriksson JG, Valle TT, Hämäläinen H, Ilanne-Parikka P, Keinänen-Kiukaanniemi S, Laakso M, Louheranta A, Rastas M, Salminen V, Uusitupa M. Prevention of type 2 diabetes mellitus by changes in lifestyle among subjects with impaired glucose tolerance. N Engl J Med 2001;344:1343-1350.

7. Luchsinger JA, Lehtisalo J, Lindström J, Ngandu T, Kivipelto M, Ahtiluoto S, Ilanne-Parikka P, Keinänen-Kiukaanniemi S, Eriksson JG, Uusitupa M, Tuomilehto J, Finnish Diabetes Prevention Study (DPS). Cognition in the finnish diabetes prevention study.Diabetes Res Clin Pract. 2015 Jun;108(3):e63-6.

8. Lindström J, Louheranta A, Mannelin M, Rastas M, Salminen V, Eriksson J, Uusitupa M, Tuomilehto J. The Finnish Diabetes Prevention Study (DPS): Lifestyle intervention and 3-year results on diet and physical activity. Diabetes Care 2003;26:3230-3236.

9. Lehtovirta M, Soininen H, Helisalmi S, Mannermaa A, Helkala EL, Hartikainen P, Hanninen T, Ryynanen M, Riekkinen PJ. Clinical and neuropsychological characteristics in familial and sporadic Alzheimer's disease: relation to apolipoprotein E polymorphism. Neurology 1996;46:413-419.

10. Ovaskainen M, Valsta L, Lauronen J. The compilation of food analysis values as database for dietary studies: The finnish experience. Food Chemistry 1996;57:133136.

11. Lakka TA \& Salonen JT. Intra-person variability of various physical activity assessments in the Kuopio Ischaemic Heart Disease Risk Factor Study. Int J Epidemiol 1992;21:467-472.

12. Morris JC, Heyman A, Mohs RC, Hughes JP, van Belle G, Fillenbaum G, Mellits ED, Clark C. The Consortium to Establish a Registry for Alzheimer's Disease (CERAD). Part I. Clinical and neuropsychological assessment of Alzheimer's disease. Neurology 1989;39:1159-1165.

13. Reitan RM. The relation of the trail making test to organic brain damage. J Consult Psychol 1955;19:393-394.

14. Chandler MJ, Lacritz LH, Hynan LS, Barnard HD, Allen G, Deschner M, Weiner MF, Cullum CM. A total score for the CERAD neuropsychological battery. Neurology 2005;65:102-106. doi: 10.1212/01.wnl.0000167607.63000.38

15. Box GEP \& Cox DR. An analysis of transformations. Journal of the Royal Statistical
Society 1964;26:211-252.

16. Smith PJ, Blumenthal JA, Babyak MA, Craighead L, Welsh-Bohmer KA, Browndyke JN, Strauman TA, Sherwood A. Effects of the dietary approaches to stop hypertension diet, exercise, and caloric restriction on neurocognition in overweight adults with high blood pressure. Hypertension 2010;55:1331-1338. doi: 10.1161/ HYPERTENSIONAHA.109.146795.

17. Eskelinen MH, Ngandu T, Helkala EL, Tuomilehto J, Nissinen A, Soininen H, Kivipelto M. Fat intake at midlife and cognitive impairment later in life: a population-based CAIDE study. Int J Geriatr Psychiatry 2008;23:741-747. doi: 10.1002/gps.1969.

18. Devore EE, Stampfer MJ, Breteler MM, Rosner B, Hee Kang J, Okereke O, Hu FB, Grodstein F. Dietary fat intake and cognitive decline in women with type 2 diabetes. Diabetes Care 2009;32:635-640. doi: 10.2337/dc08-1741.

19. Okereke OI, Rosner BA, Kim DH, Kang JH, Cook NR, Manson JE, Buring JE, Willett WC, Grodstein F. Dietary fat types and 4-year cognitive change in community-dwelling older women. Ann Neurol 2012;72:124-134. doi: 10.1002/ ana.23593; 10.1002/ana.23593

20. Vercambre MN, Grodstein F, Kang JH. Dietary fat intake in relation to cognitive change in high-risk women with cardiovascular disease or vascular factors. Eur J Clin Nutr 2010;64:1134-1140. doi: 10.1038/ejen.2010.113.

21. Luchsinger JA, Tang MX, Shea S, Mayeux R. Caloric intake and the risk of Alzheimer disease. Arch Neurol 59:1258-1263.

22. Laitinen MH, Ngandu T, Rovio S, Helkala EL, Uusitalo U, Viitanen M, Nissinen A, Tuomilehto J, Soininen H, Kivipelto M. Fat intake at midlife and risk of dementia and Alzheimer's disease: a population-based study. Dement Geriatr Cogn Disord 2006;22:99-107.

23. Vercambre MN, Boutron-Ruault MC, Ritchie K, Clavel-Chapelon F, Berr C. Longterm association of food and nutrient intakes with cognitive and functional decline: a 13-year follow-up study of elderly French women. Br J Nutr 2009;102:419-427. doi: $10.1017 /$ S0007114508201959.

24. Ortega RM, Requejo AM, Andres P, Lopez-Sobaler AM, Quintas ME, Redondo MR, Navia B, Rivas T. Dietary intake and cognitive function in a group of elderly people. Am J Clin Nutr 1997;66:803-809.

25. Buchman AS, Boyle PA, Yu L, Shah RC, Wilson RS, Bennett DA. Total daily physical activity and the risk of $\mathrm{AD}$ and cognitive decline in older adults. Neurology 2012;78:1323-1329. doi: 10.1212/WNL.0b013e3182535d35.

26. Geda YE, Roberts RO, Knopman DS, Christianson TJ, Pankratz VS, Ivnik RJ, Boeve $\mathrm{BF}$, Tangalos EG, Petersen RC, Rocca WA. Physical exercise, aging, and mild cognitive impairment: a population-based study. Arch Neurol 2010;67:80-86. doi: 10.1001/archneurol.2009.297.

27. Devore EE, Kang JH, Okereke O, Grodstein F. Physical activity levels and cognition in women with type 2 diabetes. Am J Epidemiol 2009;170:1040-1047. doi: 10.1093/ aje/kwp224.

28. Tolppanen AM, Solomon A, Kulmala J, Kareholt I, Ngandu T, Rusanen M, Laatikainen T, Soininen H, Kivipelto M. Leisure-time physical activity from midto late life, body mass index, and risk of dementia. Alzheimers Dement 2014; doi: 10.1016/j.jalz.2014.01.008. [Epub ahead of print]

29. Foubert-Samier A, Le Goff M, Helmer C, Peres K, Orgogozo JM, BarbergerGateau P, Amieva H, Dartigues JF. Change in leisure and social activities and risk of dementia in elderly cohort. J Nutr Health Aging 2014;18:876-882. doi: 10.1007/ s12603-014-0475-7 [doi].

30. Baker LD, Frank LL, Foster-Schubert K, Green PS, Wilkinson CW, McTiernan A, Plymate SR, Fishel MA, Watson GS, Cholerton BA, Duncan GE, Mehta PD, Craft S. Effects of aerobic exercise on mild cognitive impairment: a controlled trial. Arch Neurol 2010;67:71-79. doi: 10.1001/archneurol.2009.307.

31. Suzuki T, Shimada H, Makizako H, Doi T, Yoshida D, Ito K, Shimokata H, Washimi Y, Endo H, Kato T. A randomized controlled trial of multicomponent exercise in older adults with mild cognitive impairment. PLoS One 2013;8:e61483. doi: 10.1371/journal.pone.0061483.

32. Baker LD, Frank LL, Foster-Schubert K, Green PS, Wilkinson CW, McTiernan A, Cholerton BA, Plymate SR, Fishel MA, Watson GS, Duncan GE, Mehta PD, Craft $\mathrm{S}$. Aerobic exercise improves cognition for older adults with glucose intolerance, a risk factor for Alzheimer's disease. J Alzheimers Dis 2010;22:569-579. doi: 10.3233/ JAD-2010-100768.

33. Dahl AK, Hassing LB, Fransson EI, Gatz M, Reynolds CA, Pedersen NL. Body mass index across midlife and cognitive change in late life. Int J Obes (Lond) 2013;37:296-302. doi: 10.1038/ijo.2012.37.

34. Reijmer YD, van den Berg E, Dekker JM, Nijpels G, Stehouwer CD, Kappelle LJ, Biessels GJ. Development of Vascular Risk Factors over 15 Years in Relation to Cognition: The Hoorn Study. J Am Geriatr Soc 2012;60:1426-1433. doi: 10.1111/j.1532-5415.2012.04081.x.

35. Lo AH, Pachana NA, Byrne GJ, Sachdev PS, Woodman RJ. Relationship between changes in body weight and cognitive function in middle-aged and older women. Int J Geriatr Psychiatry 2012;27:863-872. doi: 10.1002/gps.2797.

36. Driscoll I, Espeland MA, Wassertheil-Smoller S, Gaussoin SA, Ding J, Granek IA, Ockene JK, Phillips LS, Yaffe K, Resnick SM, Women's Health Initiative Study of Cognitive Aging. Weight change and cognitive function: findings from the Women's 


\section{ASSOCIATION OF LONG-TERM DIETARY FAT INTAKE, EXERCISE, WEIGHT WITH LATER COGNITIVE FUNCTION}

Health Initiative Study of Cognitive Aging. Obesity (Silver Spring) 2011;19:15951600. doi: 10.1038/oby.2011.23.

37. Sergi G, De Rui M, Coin A, Inelmen EM, Manzato E. Weight loss and Alzheimer's disease: temporal and aetiologic connections. Proc Nutr Soc 2013;72:160-165. doi: $10.1017 /$ S0029665112002753.

38. Siervo M, Nasti G, Stephan BC, Papa A, Muscariello E, Wells JC, Prado CM, Colantuoni A. Effects of intentional weight loss on physical and cognitive function in middle-aged and older obese participants: a pilot study. J Am Coll Nutr 2012;31:7986.

39. Espeland MA, Rapp SR, Bray GA, Houston DK, Johnson KC, Kitabchi AE, Hergenroeder AL, Williamson J, Jakicic JM, van Dorsten B, Kritchevsky SB, for the Action for Health In Diabetes (Look AHEAD) Movement and Memory Subgroup and the Look AHEAD Research Group. Long-term Impact of Behavioral Weight Loss Intervention on Cognitive Function. J Gerontol A Biol Sci Med Sci 2014;69:1101-1108. doi: 10.1093/gerona/glu031.

40. Tolppanen AM, Solomon A, Soininen H, Kivipelto M. Midlife vascular risk factors and Alzheimer's disease: evidence from epidemiological studies. J Alzheimers Dis 2012;32:531-540. doi: 10.3233/JAD-2012-120802 [doi].

41. Liu CL, Lin MH, Peng LN, Chen LK, Su CT, Liu LK, Chen LY. Late-life metabolic syndrome prevents cognitive decline among older men aged 75 years and over: oneyear prospective cohort study. J Nutr Health Aging 2013;17:523-526. doi: 10.1007/ s12603-013-0010-2 [doi].

42. Schneider $N \&$ Yvon C. A review of multidomain interventions to support healthy cognitive ageing. J Nutr Health Aging 2013;17:252-257. doi: 10.1007/s12603-0120402-8; 10.1007/s12603-012-0402-8.

43. Lindström J, Peltonen M, Eriksson JG, Ilanne-Parikka P, Aunola S, KeinänenKiukaanniemi S, Uusitupa M, Tuomilehto J, Finnish Diabetes Prevention Study (DPS). Improved lifestyle and decreased diabetes risk over 13 years: long-term follow-up of the randomised Finnish Diabetes Prevention Study (DPS). Diabetologia 2013;56:284-293. doi: 10.1007/s00125-012-2752-5. 